\title{
A ABORDAGEM PBL (PROBLEM BASED LEARNING) EM UM CURSO TÉCNICO EM ENFERMAGEM: ELEMENTOS AUTOBIOGRÁFICOS DA PRÁTICA DOCENTE EM ANATOMIA HUMANA
}

\author{
PBL (PROBLEM BASED LEARNING) APPROACH IN A NURSING \\ TECHNICAL COURSE: AUTOBIOGRAPHICAL ELEMENTS OF TEACHING \\ PRACTICE IN HUMAN ANATOMY
}

\author{
Wanhinna Regina Soares da Silva ${ }^{1}$ \\ Douglas Pereira de Souza ${ }^{2}$ \\ Sebastião Rodrigues-Moura ${ }^{3}$
}

\begin{abstract}
Resumo: Nesta pesquisa, ancoramos a nossa investigação em analisar os elementos didáticos da ação docente de um professor enfermeiro da educação profissional por meio da abordagem Problem Based Learning (PBL) no ensino de anatomia humana. Trata-se de um estudo de abordagem qualitativa, de cunho autobiográfico, em que nos apropriamos da Análise Textual Discursiva (ATD) como técnica de análise para a argumentação dos registros extraídos de um diário de docência; material empírico do qual emergiram resultados relacionados a (i) elementos da prática docente reflexiva, (ii) apreensão dos conhecimentos técnico-científicos dos estudantes, e (iii) potencialidades do uso da PBL na mediação pedagógica em saúde. Infere-se que o processo pode oportunizar a capacidade de integrar a realidade do estudante à educação profissional, bem como delinear contribuições para a educação em saúde, a fim de fortalecer a construção do conhecimento científico a profissionais de forma integral e humanizada.
\end{abstract}

Palavras-chave: Educação em Saúde; Problem Based Learning; Anatomia.

\begin{abstract}
In this research, we anchor our research in analyzing the didactic elements of the teaching action of a nurse teacher of professional education through the Problem Based Learning (PBL) approach in teaching human anatomy. This is a qualitative approach study, with autobiographical nature, in which we appropriate Discursive Textual Analysis (DTA) as an analysis technique for the argumentation of the records extracted from a teaching diary; empirical material from which emerged results related to (i) elements of reflective teaching practice, (ii) apprehension of students' technical-scientific knowledge, and (iii) potentialities of the use of PBL in health pedagogical mediation. It is inferred that the process can provide the ability to integrate student reality into professional education, as well as delineate contributions to health education, in order to strengthen the construction of scientific knowledge to professionals in an integral and humanized way.
\end{abstract}

Keywords: Health Education; Problem Based Learning; Anatomy.

\footnotetext{
${ }^{1}$ Mestranda em Saúde Pública pela Universidade de São Paulo (PPG-SP/UPS). Técnica administrativa do Instituto Federal de Educação, Ciência e Tecnologia do Pará (IFPA), Parauapebas, Pará, Brasil. E-mail: regina_wrr@hotmail.com

2 Mestre em energia pela Universidade Federal do ABC (PPG-ENE/UFABC). Professor na Faculdade de Ensino Superior da Amazônia Reunida (FESAR), Redenção, Pará, Brasil. E-mail: douglasdc7@hotmail.com

${ }^{3}$ Doutorando em Educação em Ciências e Matemática pela Universidade Federal do Mato Grosso (UFMT). Professor do Instituto Federal de Educação, Ciência e Tecnologia do Pará (IFPA), Parauapebas, Pará, Brasil. E-mail: sebastiao.fisica@gmail.com
} 


\section{Reflexões iniciais}

Em conformidade com o Ministério de Saúde (BRASIL, 2006), a prática de Educação em Saúde envolve um processo educativo para a construção de conhecimentos político-pedagógicos, de modo a desenvolver olhares crítico-reflexivos para aqueles que buscam a autonomia pelo cuidado individual e coletivo, pautados em ações sociais. A Enfermagem, enquanto segmento prioritário em saúde, é composta por três categorias profissionais: enfermeiros, técnicos e auxiliares em enfermagem (BARBOSA et al., 2011), a qual cabe o assistir, o cuidar, o pesquisar e o educar, sendo este último um dos principais papéis que o enfermeiro assume.

Formar recursos humanos tem se tornado uma atividade de grande responsabilidade para o enfermeiro que irá capacitar profissionais que estão diretamente envolvidos no cuidado ao ser humano (LIMA; APOLINÁRIO, 2011; WALL; PRADO; CARRARO, 2008). Neste sentido, chego ${ }^{4}$ a reflexão de que mesmo o enfermeiro sendo um profissional não licenciado, ao longo dos anos sempre coube a ele a formação adequada do técnico de enfermagem, seja na assistência a qual the cabe como coordenador de equipe, passar o conhecimento dos procedimentos aos técnicos, seja na escola onde de fato o enfermeiro assume o papel de docente da educação profissional em saúde.

O técnico em enfermagem exerce atividade de nível médio, que envolve orientação e acompanhamento do trabalho de enfermagem no grau de auxiliar, e participação no planejamento e no cuidado de enfermagem (PEREIRA, 2007; BARBOSA et al. 2011). São profissionais com a função de intervir no contexto social por meio do enfrentamento dos problemas de saúde da população (FEUERWERKER; SENA, 1999; LIMA; APOLINÁRIO, 2011).

Quando penso sobre a prática deste profissional, percebo que é preciso considerar o contexto da construção do seu conhecimento técnico-científico no ensino profissionalizante, de modo que os problemas que o mesmo encarará na vivência profissional, podem ser intensificados ao passarem por uma formação deficitária.

\footnotetext{
${ }^{4} \mathrm{O}$ uso do verbo flexionado em primeira pessoa do singular é justificado pelo fato do uso da abordagem metodológica da narrativa autobiográfica. Não se trata, portanto, de erro na redação ou incoerência, mas destaca a minha postura enquanto professora-pesquisadora da própria prática, cabendo destacar que alguns momentos serão usados tempos verbais na primeira pessoa do plural, haja vista que é um posicionamento da relação existente entre orientando-pesquisa-orientador(es) e, ao utilizar verbos acompanhado do pronome "se", será uma postura que não demostra um apontamento pessoal, mas uma imparcialidade ao discorrer sobre determinado fenômeno observado ao longo do processo de intervenção.
} 
São inúmeros os desafios na construção do conhecimento técnico-científico dos profissionais do nível médio em enfermagem, entre eles destaca-se: manter os professores atualizados; falta de conhecimento dos enfermeiros no processo de ensinar; falta de material didático, audiovisual, biblioteca, laboratório e campo de estágio adequado; falta de tempo para passar o conteúdo proposto e para se dedicar mais à docência, além do acúmulo de atividades profissionais (LIMA; APOLINÁRIO, 2011).

Os desafios ligados a educação profissional perpetuam toda a história desta modalidade de ensino (LIMA; APOLINÁRIO, 2011; CARDOSO; MONTEIRO, 2018). Desde suas origens, a formação profissional foi permanentemente vista como subeducação, reservada às classes menos favorecidas, destinando-se a amparar os órfãos e os demais desvalidos da sorte, assumindo um caráter assistencialista que tem marcado todo o seu legado.

Acerca disso Gomes (2010) enfatiza que:
a herança escravista brasileira influenciou de forma preconceituosa as relações sociais e o modo como a sociedade via a educação e a formação profissional. [..] inicialmente os aprendizes foram os índios mais fortes e jovens, os escravos e, posteriormente, órfãos, mendigos e outros desgraçados (p. 53-54).

Neste sentido, reconheço que a educação profissional sempre foi declinada e que atualmente no campo da saúde o preconceito e a desvalorização ainda perpetuam na formação dos técnicos em enfermagem. Para Lima e Apolinário, (2011), a docência em nível profissionalizante de enfermagem é um trabalho importante e exigente, entretanto com pouco reconhecimento e status profissional, na qual a realidade é traduzida por baixos salários, pouca perspectiva de progressão na carreira, contrato de trabalho temporário e falta de condições e de infraestrutura para a realização do trabalho.

Somadas a todas estas dificuldades, a formação docente também é uma preocupação, tendo em vista que o profissional bacharel desta área é formado para trabalhar na assistência, no processo do cuidar, não voltada para o educar. Dessa forma, refletir sobre o processo de formação profissional também requer, de certo modo, perceber, como se deu a constituição do ser professor, no desenvolvimento de sua prática educativa (CARDOSO; MONTEIRO, 2018).

Em relação às dificuldades relacionadas à falta de formação do professor, os alunos do ensino médio de enfermagem relatam que o enfermeiro professor adota um método de aula e não muda, ensina da mesma forma independente da aula que ministra ou, ainda, fica muito longe da prática assistencial, preso somente à teoria obtida através dos livros (LIMA; APOLINÁRIO, 2011). Assim, percebo que a educação profissional na 
enfermagem está pautada na simples transmissão de conhecimento segmentado e tecnicista que não confere ao aluno o conhecimento integral.

Neste sentido, entendo que a educação profissional na área da saúde precisa tornar-se menos tecnicista/tradicional e voltada a um processo de ensino-aprendizagem mais reflexivo por parte dos docentes, formando profissionais mais críticos e emancipados da sua própria construção do conhecimento, tirando do professor o mero papel de transmissor do conhecimento para aquele que emancipa o aluno em uma formação integral.

Nesse processo, mostram-se, particularmente, importantes as metodologias ativas, alicerçadas em princípios teórico-metodológicos significativos, nas e pelas quais o aluno é estimulado a autogerenciar/autogovernar o seu processo de construção do conhecimento. Para Backes et al., (2010), as metodologias ativas privilegiam a problematização, por meio das quais os indivíduos são estimulados a pensar, a refletir, a criar, a indagar-se, a ressignificar continuamente as suas descobertas.

Apesar de na enfermagem as três classes de profissionais terem papéis distintos no cuidar, algumas disciplinas são comuns a formação de todos. A Anatomia Humana, por exemplo, é uma disciplina básica que todo estudante tem de aprender ao adentrar um curso da área da saúde. Entretanto, alguns discentes apresentam dificuldades para o aprendizado das estruturas anatômicas por motivos variados, desde a dificuldade com suas terminologias à falta de motivação ou atenção (BRAZ, 2009).

Para Salbego et al. (2015) essa área é uma das ciências médicas mais antigas, pela qual se estudam as estruturas do corpo humano e suas respectivas funções. O estudo da Anatomia Humana é indispensável, servindo de base para o aprendizado da clínica, agregando conhecimento sobre o corpo humano que favorecerão a realização do exame físico de forma correta e o direcionamento da história clínica (REIS et al., 2013).

São diversos os métodos e metodologias aplicados ao ensino, mas os alunos ainda apresentam dificuldades em aprender os conceitos e conteúdos estudados (COSTA, GILLIENE; COSTA, GILLIANE; LINS, 2012). Dentre as metodologias, encontram-se aulas expositivas, aulas práticas com uso de cadáveres humanos dissecados, que é uma das formas mais antigas e utilizadas no ensino da disciplina; aulas práticas com uso de modelos anatômicos, entre outras, e, recentemente, incluiu-se o processo de aprendizagem autodirigido baseado em problemas que, segundo o autor mencionado anteriormente, essa nova ferramenta conduz à melhoria do desempenho do aluno, já que facilita o aprendizado de conteúdos, permitindo a construção efetiva do conhecimento. 
Para Damasceno e Cória-Sabini (2003), na escola não se deveria apenas aprender conceitos, mas também que sejam desenvolvidos nos alunos, habilidades e procedimentos técnicos que lhes permitam a atuação nos diversos campos de aplicação das disciplinas que compõem o currículo, no entanto parte das vezes isto não ocorre, pois esta autonomia do aluno só será desenvolvida se a aprendizagem ocorrer de forma significativa, em que a teoria seja articulada continuamente com a prática.

Nesse sentido, as instituições têm sido estimuladas a valorizarem uma profissionalização que priorize o humanismo, a equidade e a qualidade da assistência. Seguindo no sentido contrário do ensino tradicional, a Problem Based Learning ( $\left.\mathrm{PBL}^{5}\right)$ surge como uma quebra de paradigma no ensino, que levará os alunos a identificarem suas necessidades reais de aprendizagem (BORGES; ALENCAR, 2014; WALL; PRADO; CARRARO, 2008; MIRANDA JUNIOR, 2016).

Do exposto, aportamo-nos na metodologia conhecida como Aprendizagem Baseada em Problemas (ABP) ou Problem Based Learning (PBL) para investigar situações didáticas da prática docente em um curso técnico em enfermagem no ensino de Anatomia Humana. Reconhecendo a PBL como um método muito utilizado na educação na área da saúde, tendo capacidade para diminuir as fragilidades do ensino da anatomia humana tradicional, ancoramo-nos ao objetivo geral de analisar os elementos didáticos da ação docente de um professor enfermeiro da educação profissional por meio da abordagem Problem Based Learning (PBL) no ensino de Anatomia Humana em um curso técnico em enfermagem.

\subsection{A formação do docente enfermeiro que atua na educação profissional}

Discutiremos a formação dos docentes das instituições de educação profissional e tecnológica, traçando em linhas gerais, uma concepção a respeito da formação docente compatível com o perfil das instituições de educação profissional. Trabalharemos com o foco na formação didático-político-pedagógica destes professores.

$\mathrm{Na}$ educação profissional tem-se formado profissionais que são formados por outros que "atuam" como professores, embora, na maioria das vezes, não tenham formação específica para esse fim.

\footnotetext{
5 A partir deste momento, ao tratarmos da abordagem Problem Based Learning, a citaremos apenas em sua abreviatura, na forma intitulada PBL, sem perda de sentido ou significação no contexto ao qual será discutido.
} 
Esse é um problema estrutural do sistema educacional e da própria sociedade brasileira, pois enquanto para exercer uma profissão liberal é necessário a correspondente formação profissional, para exercer o magistério, principalmente, no que tange à docência para a educação profissional, não há muito rigor na exigência de formação na correspondente profissão de professor (MOURA, 2008).

Oliveira e Silva (2012) destacam ainda a importância da formação pedagógica como pré-requisito para o exercício da docência, o que torna necessário a revisão das formas de admissão de novos professores. Na maioria das vezes, o que se valoriza nos processos seletivos de admissão de professores são os conhecimentos específicos do professor em relação a sua área de formação, bem como sua experiência profissional e titulações na área comum à de formação inicial e não em suas experiências, capacidades e habilidades voltados à docência.

Para Libâneo (2017), a formação profissional para o magistério requer

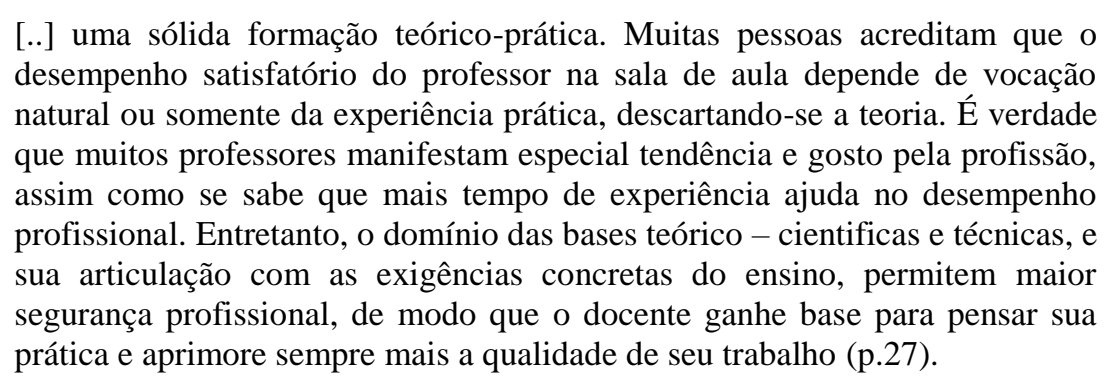

Sobre a formação docente, a Lei de Diretrizes e Bases para a Educação Nacional - LDB n 9 9.394/96, destaca que para a educação básica a nível médio “a preparação para o exercício do magistério superior far-se-á em nível de pós-graduação, prioritariamente em cursos de mestrado e doutorado". Dessa forma, pensando também nos sujeitos dessa formação continuada sem deixar a um segundo plano as necessidades dos sistemas de ensino e a qualidade de tal formação, é necessário que ela ocorra, inicialmente, por meio de cursos de pós-graduação lato sensu, os quais poderão ser a base de futuros cursos stricto sensu.

A pós-graduação lato sensu aqui proposta precisa ter características diferenciadas dos cursos de especialização comuns do país, a fim de que possa cumprir a função a que se destinam. É necessário que a carga horária seja bem maior que o limite mínimo de 360 horas e, igualmente importante, que se incluam estágios de prática docente e de observação e/ou prática no mundo do trabalho na área profissional em que o docente atua ou atuará após concluir a respectiva formação (MOURA, 2008). 


\subsection{Ensino-aprendizagem a partir de problemas}

Torna-se um desafio ao docente contribuir com a educação cidadã diante da necessidade de resgatar valores condizentes com a sociedade contemporânea. Este desafio leva o professor a perceber seu novo papel, de acordo com os princípios de ensinoaprendizagem adotados, como saber lidar com os erros, estimular a aprendizagem, ajudar os alunos a se organizarem, educar através do ensino, entre outros (COSTA, 2001).

Notamos que o processo de globalização trouxe velocidade à informação e acostumados a esta rapidez na transmissão de dados, uma vez que a geração de estudante que temos hoje anseia por métodos de ensino que acompanham esses avanços. Não podemos mais ensinar por métodos tradicionais por meio da transmissão de conteúdos, pois tal ação não tem motivado o aluno, não agrega valores e não o aproxima do seu papel em comunidade.

Dessa maneira, é preciso que nós professores possamos buscar métodos que emancipem este aluno na busca por conhecimento, para que este seja capaz de construir as soluções de seus problemas e de uma sociedade. Neste sentido, o aprendizado baseado em problemas surge como uma proposta pedagógica que consiste no ensino centrado no estudante e baseado na solução de problemas. O princípio de que os seres humanos aprendem a partir de experiências do cotidiano, no qual se apresentam vários problemas que necessitam de soluções, muitas vezes imediatas, foi a base do desenvolvimento deste método (BORGES et al., 2014).

As aulas tradicionais têm ofertados conceitos, teorias e conteúdos ao aluno, entretanto na comunidade ele se deparará com problemas que precisam de soluções imediatas. Como o que ocorre ao profissional que quando aluno não foi preparado para resolver problemas e hoje os encara diariamente. Nessa situação, o processo de ensinoaprendizagem para esta geração precisa incentivar o aluno de fato a buscar seu conhecimento, a construir o seu aprendizado, a formar personalidades e opiniões para que em sociedade ele seja de fato um cidadão ativo, crítico e reflexivo.

Todavia, o professor precisa mediar e direcionar o estudante ao objetivo, para que desse modo o aluno possa adquirir habilidades como fazer consultas em livros, entender o que se lê, tomar notas, fazer síntese, redigir conclusões, interpretar gráficos e dados, realizar experiências e discutir os resultados obtidos e, sobretudo, usar instrumentos de medida quando necessário, bem como compreender as relações que existem entre os problemas atuais e o desenvolvimento técnico-científico (COSTA, 2001). 
Esse novo método propicia um papel inovador ao professor no processo de ensinoaprendizagem, entretanto a sua falta de experiência com os fundamentos teóricos e práticos da PBL tem sido uma das grandes limitações para sua adoção nas escolas médicas, especialmente naquelas que se fundamentaram e se desenvolveram dentro do ensino tradicional (BORGES et al., 2014).

\subsection{Uso e aplicação da abordagem PBL}

Apesar de utilizado anteriormente por outras áreas do conhecimento, a PBL foi introduzida no ensino de Ciências da Saúde na McMaster University, Canadá, em 1969, sob a coordenação de Howard S. Barrows (BORGES et al., 2014), tendo como base os princípios da escola ativa em que os alunos aprendem a aprender e se preparam para resolver problemas relativos às suas futuras profissões. Dessa forma, sendo a PBL uma proposta de reestruturação curricular, organiza-se um elenco de situações que o aluno deverá saber/dominar, o qual deverá analisar situação por situação para que se determine que conhecimentos o aluno deverá possuir para cada uma delas; estes são os denominados temas de estudo (VIGNOCHI, 2009).

Cada um desses temas de estudo será transformado em um problema a ser discutido em um grupo tutorial que funciona como apoio para os estudos. Cada grupo será composto de um tutor com 8 a 10 alunos. (VIGNOCHI, 2009; BORGES et al., 2014). Dentre os alunos, um será o coordenador e outro será o secretário, mudando de sessão a sessão, para que todos exerçam essas funções. No grupo, os alunos são apresentados a um problema pré-elaborado, o qual será discutido em grupo e deve incentivar o levantamento de hipóteses para explicá-lo (VIGNOCHI, 2009).

Borges et al., (2014) define os papéis dos estudantes participantes do grupo tutorial
estudante coordenador: é um estudante do grupo que deverá auxiliar a facilitação durante a discussão no grupo tutorial. Estudante secretário: é um estudante do grupo que realizará as anotações referentes à discussão, garantindo que as várias etapas da discussão sejam anotadas de forma que o grupo não se perca na discussão e não volte a pontos que já foram discutidos anteriormente. Demais estudantes: deverão se esforçar para realizar uma boa discussão do problema, de forma metódica, respeitando as diretrizes do coordenador do grupo (p. 304).

Do exposto e, a partir desta ação, alguns objetivos serão traçados para melhor estudá-lo; além de pesquisas e estudos que serão propostos. Uma carga horária é prevista para o estudo de cada problema; o grupo deve organizar-se para cumpri-la, a fim de poder 
passar para o problema seguinte. O problema deve ser conciso e isento de distrações, deve dirigir a aprendizagem a um número limitado de itens, focalizar apenas itens que possam ter alguma explicação baseada no conhecimento prévio dos alunos (VIGNOCHI, 2009).

Existirão ainda dentro do grupo alguns importantes passos, metodologicamente elaborados, a serem seguidos: leitura do problema; identificação e esclarecimento de termos desconhecidos; identificação dos problemas propostos pelo enunciado; formulação de hipóteses explicativas para os problemas identificados no passo anterior (os alunos se utilizam, nesta fase, dos conhecimentos de que dispõem sobre o assunto); resumo das hipóteses; formulação dos objetivos de aprendizagem (trata-se da identificação do que o aluno deverá estudar para aprofundar os conhecimentos incompletos formulados nas hipóteses explicativas); estudo individual dos assuntos levantados nos objetivos de aprendizagem; e retorno ao grupo tutorial para rediscussão do problema frente aos novos conhecimentos adquiridos na fase de estudo anterior (VIGNOCHI, 2009).

O professor nesta abordagem passa a ser chamado de tutor, pois, assume um papel diferente. Para Borges et al. (2014), ele precisa ser treinado e conhecer de antemão os objetivos de aprendizado pretendidos para cada problema. Porém, não deverá impor estes objetivos, nem resolver os problemas para os alunos, pois o processo de aprendizado é tão importante quanto o conhecimento em si, devendo intervir minimamente no processo, procurando assumir o papel de mediador, estimular o processo de aprendizagem dos estudantes, motivar o trabalho do grupo e a participação dos estudantes, bem como respeitar suas opiniões e detectar eventuais rivalidades, monopólios e inconformismos.

Para além disso, esta abordagem permite ao professor um feedback do desempenho de seus alunos e a realização de contínuas avaliações, cujos resultados poderão ser usados para a reflexão da prática didático-pedagógica do mesmo.

\subsection{Prática Docente no Ensino Profissional de Anatomia Humana}

Todo aluno com o objetivo de cursar uma área relacionada com as ciências da saúde ficará ciente que a disciplina de Anatomia Humana será ensinada e que servirá de base para o aprendizado das suas subdisciplinas (BRAZ, 2009).

Entretanto, o aluno não está familiarizado com a terminologia anatômica, visto que a maioria dos termos é derivada do latim e grego, então a linguagem médica pode ser 
difícil no início, entretanto à medida que o aluno vai aprendendo a origem dos termos, as palavras começam a fazer mais sentido à sua compreensão (BRAZ, 2009).

Para tanto, acredita-se haver necessidade de modificações das práticas didáticopedagógicas, visto que as mudanças já estão inseridas no cotidiano dos estudantes e que o processo ensino-aprendizagem deve ser condizente com a realidade que o acadêmico vivencia em sua rotina. Este processo deve ser largamente discutido entre os professores para que se apliquem propostas pedagógicas coerentes e instigando a transformação do desempenho dos sujeitos em sala de aula (FORNAZIERO et al., 2010)

\section{Encaminhamentos Metodológicos}

Trata-se de um estudo descritivo, de abordagem qualitativa. Considerada como uma pesquisa-intervenção, uma vez que além de compreender, visa intervir na situação, com vistas a modificá-la. Assim, ao mesmo tempo que realiza um diagnóstico e análise de uma determinada situação, a pesquisa-ação propõe ao conjunto de sujeitos envolvidos, mudanças que levem a um aprimoramento das práticas analisadas (SEVERINO, 2007).

Durante o exercício da docência, percebi o quão falha me fazia no ensino de Anatomia Humana pelo método tradicional e que mesmo tendo passado por dificuldades para aprender seus conteúdos na graduação, quisera ainda eu, dar continuidade ao ensino desta disciplina pelos mesmos métodos que me foram ensinados. Para tanto, com o tempo, dediquei uma maior atenção ao feedback dos alunos e conscientizei-me de que precisava buscar novos métodos de ensino para aplicar em minhas próprias aulas.

Assim, este trabalho consiste em uma pesquisa narrativa autobiográfica ${ }^{6}$ em que realizei, junto aos colaboradores da pesquisa e orientador, tecer uma reflexão sobre a minha prática docente e as ações didático-pedagógicas aqui desenvolvidas. Na maior parte da escrita, apresento verbos na primeira pessoa do singular, apesar de não ser habitual em um texto acadêmico, venho destacar que o uso da narrativa tem a intenção de deixar claro ao leitor as minhas intenções, visão de mundo e experiências durante carreira acadêmica e profissional. Para Martin (1992), essa é uma importante consideração para deixar claro o sujeito em suas falas, de como percebe o mundo como autor de suas escolhas, princípios e percepções.

\footnotetext{
${ }^{6}$ Diferimos, nesta pesquisa, narrativa autobiográfica de narrativa (auto)biográfica no sentido de a primeira referir-se a pesquisa de si mesmo, como os dados aqui apresentados da autora primeira deste artigo, e a segunda quando trata de biografias narradas por terceiros e analisadas pelo pesquisador que não compuseram as suas narrativas.
} 
Dessa maneira, apropriei-me da pesquisa narrativa autobiográfica de Ferraroti (1988) como metodologia investigativa da própria prática, pelo fato de ganhar uma correlação interpretativa e de posicionamento do ato à estrutura e da história individual e social. Tal narrativa será utilizada como método para investigar a minha própria prática, pois assim acredito que estarei assumindo uma prática reflexiva diante do atual cenário da educação.

Realizei a intervenção por meio do desenvolvimento de um curso presencial de Introdução à Anatomia Humana, planejado a partir do conceito da pesquisa como princípio educativo, pautado no uso da metodologia ativa PBL, ocorrida nas dependências de uma escola de educação profissional privada do município de Parauapebas, estado do Pará, Brazil, com alunos do primeiro período do curso técnico em enfermagem, que ainda não haviam cursado a disciplina. Inicialmente fiz a exposição do projeto à instituição para autorização da intervenção e, posteriormente, divulguei o projeto aos alunos, convidandoos para participar do mesmo.

O curso de Introdução à Anatomia Humana, foi planejado e ofertado com uma carga horária de $30 \mathrm{~h}$ de atividades para a sua execução. Antes do primeiro dia de curso, reuni com os participantes para acordar suas colaborações junto ao projeto, com a assinatura do Termo de Consentimento Livre Esclarecido (TCLE), momento no qual também apresentei o método de ensino-aprendizagem PBL, conforme Vignochi (2009) e demais referenciais da literatura; posteriormente realizei o sorteio de cinco temas presentes na ementa da disciplina Anatomia Humana, do curso técnico em enfermagem da escola profissionalizante utilizada na pesquisa, de modo ao curso ser articulado à formação profissional dos alunos.

Considerando o que diz a literatura quanto ao quantitativo máximo e mínimo de componentes do grupo tutorial da PBL, foram ofertadas 10 (dez) vagas aos alunos que desejaram participar do estudo. Durante a execução do curso 01 (um) aluno, não quis mais participar, em decorrência de problemas de saúde, finalizando o curso com 9 (nove) participantes.

Cada um desses temas de estudo foi transformado em um problema a ser discutido no grupo tutorial. No grupo, os alunos foram apresentados a um problema pré-elaborado dentro da temática sorteada. As aulas pautavam-se nestes materiais didáticos: A) um caso verdadeiro de saúde, noticiado na mídia; B) um caso clínico fictício, relacionado à notícia; C) atlas de anatomia; D) peças anatômicas; E) modelos humanos; e, F) animais dissecados. Os materiais A e B norteavam a PBL, já os materiais C, D, E, e F foram 
utilizados apenas como suportes auxiliares. Discutíamos em grupo o problema e em seguida os alunos levantavam hipóteses para explicá-lo, de modo a traçar objetivos para melhor estudá-lo.

É importante destacarmos que os problemas que levavam ao grupo tutorial, não necessariamente precisavam ser solucionados pelos alunos, pois o objetivo não era especificamente solucioná-lo, muito menos definir diagnósticos à patologia do paciente, tendo em vista que o diagnóstico clínico não é atividade fim do profissional técnico em enfermagem.

O foco de se trabalhar problemas originados dos casos clínicos é, portanto, ressignificar o ensino da Anatomia Humana a estes estudantes, de modo a proporcionar ao mesmos a compreensão do caso exposto, para que sejam capazes de relacionar o problema aos seus conhecimentos prévios, além de conseguir visualizar um significado para sua carreira profissional, construindo assim um novo conhecimento.

Ocorreram 10 (dez) sessões tutoriais ao longo do curso, duas sessões por semana, cada uma com carga horária de 3 (três) horas. O grupo se organizava para cumprir a carga horária a fim de poder passar para o problema seguinte, sendo uma sessão para abertura do caso e outra para o seu fechamento. Na sessão de abertura era escolhia um alunooordenador e um aluno-secretário, mudando a cada sessão de abertura de caso, para que todos pudessem exercer tais funções.

Considerando que alguns alunos poderiam não ter acesso às fontes de pesquisa, ficando impossibilitados de concluir o estudo individual, foi possibilitado que, conforme necessidade, os mesmos poderiam ter acesso a laboratórios de clínica, laboratórios de informática e à biblioteca, visando a garantir a eficácia do processo de ensinoaprendizagem.

No diário de docência ${ }^{7}$, foram registrados o relato de como discorreu (e ocorreu) a prática pedagógica em cada sessão tutorial, com anotações e registros dos elementos didático-pedagógicos utilizados na mesma e o feedback dos alunos para a PBL. Assim, a narrativa autobiográfica realizada no diário, utilizado como meio de registro da ação docente, servirá ainda de instrumento para coleta dos dados e enquanto material empírico

\footnotetext{
${ }^{7}$ Ressalto que o diário de docência faz referência a um instrumento de coleta de dados (uma variação do diário de campo), porém apenas com registros das atividades docentes, muito utilizado em nossas pesquisas qualitativas. São notas de campo no qual são feitos registros, observações e anotações da prática pedagógica do professor, material empírico principal da nossa pesquisa, que pode ser feito simplesmente em um caderno, em um fichário, em blocos de anotações, dentre outros recursos e materiais (RODRIGUESMOURA, 2016).
} 
para a análise dos resultados. Desse modo, para a avaliação da intervenção pedagógica foram considerados os principais fragmentos do diário de docência.

Para a análise dos resultados presentes no diário de docência, foi utilizada a Análise Textual Discursiva (ATD), proposta por Moraes e Galiazzi (2016), considerando as quatro fases, a citar (i) uma releitura do diário de docência, (ii) a desconstrução dos textos para unitarizá-los, (iii) o registro dos fragmentos em eixos de análise, categorizando-os; e, por fim, (iv) a tessitura de argumentação das análises estabelecidas no diário de docência.

Após a leitura minuciosa das minhas anotações no diário de docência, os elementos em comuns foram agrupados em eixos descritos a seguir: (I) Elementos didáticos da prática docente reflexiva; (II) Apreensão dos conhecimentos técnicocientíficos dos estudantes; e, (III) Potencialidades do uso da PBL na mediação pedagógica para a Educação em Saúde.

\section{Resultados e discussões}

Os dados constantes nos eixos anteriores descritos são, portanto, resultantes do trabalho da colaboração entre o professor-pesquisador do curso, das orientações acadêmicas discutidas e da colaboração de colegas da área de formação, frente à proposta, os quais são discutidos a partir de elementos de uma argumentação autobiográfica da autora principal deste trabalho no contexto da prática docente reflexiva aportado na literatura, em colaboração com os coautores da pesquisa, no contexto da docência pautada na prática reflexiva por meio da abordagem PBL na educação profissional em enfermagem.

\section{(I) Elementos da prática docente reflexiva}

Frente à prática de intervenção pedagógica, destaco que os elementos da prática docente identificados fazem referência à formação reflexiva, ao planejamento didáticopedagógico e, sobretudo, à avaliação da aprendizagem dos estudantes.

Início esta análise a partir do fragmento extraído do diário de docência, descrevendo uma visão sobre a importância de sua prática para a educação profissional, pois

sei a importância que faz um profissional humanizado na assistência clínica, todavia para que nossos centros de saúde tenham bons profissionais, precisamos que nossos órgãos de educação tenham bons formadores. Apesar 
de me sentir desvalorizada na educação, com remuneração muito a baixo a de um profissional da clínica, sem plano de cargos e carreiras, na maioria das vezes sem direitos trabalhistas dignos, além da falta de estrutura e de materiais didáticos, acredito que bons profissionais necessitam de bons professores. Assim, sou motivada a seguir o sinuoso caminho da docência, por acreditar na minha capacidade de colaborar para a melhoria do atual cenário da educação em saúde, através da formação integral de outros profissionais que irão para assistência com uma formação de qualidade. Para isso, acredito que necessariamente tornar-me um professor investigador, ser reflexiva em minha prática, são fatores necessários para que eu possa enxergar se tenho seguido o caminho a qual me propus (EXCERTO DO DIÁRIO DE DOCÊNCIA, 2018).

Do explanado acima, destacamos que o professor investigador precisa ser também reflexivo, mas trata-se de uma condição necessária e não de uma condição suficiente para a sua prática. Desse modo, a reflexão deve ter como principal objetivo o fornecimento ao professor de informações corretas e autênticas sobre a sua ação, as razões para a sua ação, e as consequências dessa ação para com a realidade, de modo a construir a aprendizagem, tornar-se um profissional mais crítico e reflexivo sobre a sua ação com vistas ao enfretamento de problemas complexos (FERNANDES et al., 2005).

Assim, a qualidade e a natureza da reflexão são mais importantes do que a sua simples ocorrência. Esta perspectiva pressupõe que ensinar vai além da transmissão, compreende o saber fazer, quando fazer e por que fazer. É uma busca constante, com o objetivo de criar condições para que aconteça a aprendizagem (OLIVEIRA; SERRAZINA, 2002; BORGES; ALENCAR, 2014). Neste sentido, esta busca precisa estar atrelada a um elemento da didática que possa alinhar a mesma, o chamado "planejamento didático-pedagógico".

Inspirados no trabalho de Pereira (2007) e, para que a investigação não se desvirtue do caminho da aprendizagem, é preciso traçar métodos, conteúdos e objetivos bem planjejados como estratégias inovadoras para o ensino em Ciências da Saúde. No tocante da didática temos visto que o planejamento escolar é uma "atividade que orienta a tomada de decisões da escola e dos professores em relação às situações docentes de ensino aprendizagem, tendo em vista alcançar os melhores resultados." (LIBÂNEO, 2017, p.27). Diante disso, destaca-se que

como docente hoje busco antes de tudo, planejar de que forma pretendo conduzir o processo de ensino-aprendizagem, traço objetivos para que minha ação docente possua pontos a serem alcançados, programo o conteúdo de fato a ser usado, busco uma metodologia que considere os aspectos sociais e culturais dos alunos, busco materiais didáticos dinâmicos e tecnologia da informação para tornar a aula o quanto mais interessante e significativa possível, entretanto, tenho notado que o mais importante não é realizar um belo planejamento e segui-lo à risca, mas ter a capacidade de preparar-me para encontrar com alunos das mais diferentes personalidade, com experiências múltiplas, sabendo eu como agir diante das diversas vivências e vir a fazer adaptações continuas neste planejamento, buscando melhores resultados. 
Buscar como conduzir o assunto ao aluno que já tem conhecimento sobre, e também ao aluno que nunca viu nenhum termo anatômico na vida, é o que faz de mim um professor investigador. O bom professor, a boa prática, e principalmente o bom planejamento docente é aquele que nunca está terminantemente finalizado, mas um plano em constante metamorfose a qual possa ser adaptado as diversas necessidades educativas (EXCERTO DO DIÁRIO DE DOCÊNCIA, 2018).

Para tal, a boa prática fará também com que o professor perceba o crescimento de seu aluno, potencialmente. A cada dia tenho percebido que para ter um aluno crítico, com papel social ativo, não é preciso que eu the transmita meus conhecimentos, mas que eu possa conduzi-lo à busca por si próprio, tornando-se um profissional crítico, investigador, emancipado de suas ações, levando tais aprendizagem para a sua vida profissional PASCHOAL; MANTOVANI; MÉIER, 2007; SILVA; SEIFFERT, 2009).

Diante das observações registradas no diário de docência, observa-se ainda que

as reflexões na prática docente têm levantado questionamentos em vários elementos de minha didática. Tenho me visto diante de certas limitações, e vejo que os colegas graduados em enfermagem com deficiência na formação didática como eu, também têm sido limitados por alguns elementos. O que hoje chamamos na sala de prova, é um exemplo de elemento que me leva a estas diversas reflexões, ao meu ver ela pode ser usada erroneamente como um mero método de avaliar se o "aluno aprendeu" ou pode ser de fato uma avaliação do ensino e nos levar a refletir se nossos elementos didáticos têm se combinado para propiciar a atividade fim da construção do conhecimento. Vejo que a avaliação muita das vezes tem sido realizada em prol do sistema e não como medida diagnóstica para que o professor possa de fato buscar a eficiência da prática docente. $O$ professor deve usar a avaliação da aprendizagem para saber quais os efeitos de suas aulas sob os alunos, de modo que a avaliação pode revelar a fragilidade do trabalho do professor. Portanto, para eu avaliar é de fato investigar qual a qualidade do meu ensino (EXCERTO DO DIÁRIO DE DOCÊNCIA, 2018).

Friso que o trabalho docente alienado só poderá gerar um produto discente alienado. Apenas o aluno que consegue sozinho criticar a prática de seu professor, será capaz de desvencilhar-se da alienação dele (BECKER, 2012). O professor precisa buscar novas formas de ensinar e também de avaliar seu aluno, entretanto, acredito que esta busca precisa estar pautada cientificamente na literatura, bem como, estruturalmente baseada na busca pela construção do conhecimento do aluno (KLETEMBERG; SIQUEIRA, 2003).

Luckesi (2014) fala sobre a prática da avaliação da aprendizagem que deve necessariamente partir do interesse do educador em de fato usá-la para educar o aluno, pois

a prática da avaliação da aprendizagem, em seu sentido pleno, só será possível na medida em que se estiver efetivamente interessado na aprendizagem do educando, ou seja, há que se estar interessado em que o educando aprenda aquilo que está sendo ensinado. Parece um contrassenso essa afirmação, na medida em que podemos pensar que quem está trabalhando no ensino está 
interessado em que os educandos aprendam. Todavia, não é o que ocorre (p. 36).

Faço aqui a análise de outro elemento didático ao reconhecer limitações da prática docente, uma vez que

\begin{abstract}
para mim a dificuldade da docência não está em capacitar o aluno para a execução das atividades práticas de sua profissão, mas fazer com que ele também reflita sobre qual o seu papel como profissional em sociedade. Para que possamos levar o aluno a repensar nos motivos para que estejam ali, se o motivo seria apenas aprender o nome de todas as estruturas do corpo humano ou aprender que cada estrutura anatômica faz parte de um ser humano, cidadão, a qual se deve o respeito e o comprometimento da equipe de enfermagem não devido à uma parte do seu corpo, mas como um ser holístico. Neste sentido acredito que ressignificar o ensino seja a solução para que este aluno perceba seu fundamental papel neste processo, de modo a querer fazer parte do mesmo, agindo com dignidade diante de seu paciente e prosseguindo até o fim de seu curso para alcance do objetivo de torna-se profissional (EXCERTO DO DIÁRIO DE DOCÊNCIA, 2018).
\end{abstract}

Para além do exposto, a minha prática docente tem traçado um percurso progressivo na busca pela inovação e aperfeiçoamento dentro do meu papel como docente: procurando abordagens significativas para o aluno, fazendo a ligação entre a formação profissional e a prática social, tendo-se em vista que todo professor deve ser capaz de transformar a sua prática, apesar do desafiador caminho que perpetua a saída da zona de conforto, do ensino tradicional. Por isso, cabe ao professor o papel didático de proporcionar ao aluno uma educação integral, com formação científica e humanística, por a docência ser uma atividade valiosa (WALL; PRADO; CARRARO, 2008).

É preciso ainda refletir, que o aluno concluinte do ensino médio, busca o curso técnico em enfermagem, modalidade subsequente, pode ser um jovem ou adulto que já possui responsabilidades em família e precisa trabalhar pelo seu sustento e de seus entes. Portanto, este tipo de aluno não tem motivação para ir à aula para simplesmente ouvir teorias e conceitos que não lhe fazem sentido, pois como sujeito já aspira por conhecimentos significativos, busca autonomia, precisa ser conquistado todos os dias para persistir na busca por conhecimento, mesmo quando ele sente o cansaço após o trabalho, mas que leve como experiência e vivência coletivas, para o fortalecimento e a instrumentalização do profissional da contemporaneidade (DIAS et al., 2018).

\title{
(II) Apreensão dos conhecimentos técnico-científicos dos estudantes
}

Falar sobre a apreensão do conhecimento ao aluno dentro da análise da prática é imprescindível, no excerto a seguir trago menção às dificuldades da prática pedagógica, no que tange ao fazer e ao interessar do aluno pelo conhecimento, pois 
consigo perceber o quão eu mesma posso distanciar ou desmotivar meus alunos. Apreender o interesse do meu aluno no conhecimento não tem sido tarefa fácil, pois tornar o conhecimento interessante deve partir do princípio de torna-lo significativo à realidade dos alunos. Entretanto, como adaptar o mesmo conteúdo à realidade plural dos alunos de uma turma é o que torna árdua a tarefa de professor (EXCERTO DO DIÁRIO DE DOCÊNCIA, 2018,).

É nesse sentido que observo que como professora e como pesquisadora que avaliar a minha própria atuação docente e me dedicar a avaliar a aprendizagem de meus alunos é válido e necessário; tenho crescido neste sentido, mas assumo que a trajetória é árdua e ainda perpasso pelo seu início. Ainda preciso melhorar significativamente os elementos didático-pedagógicos que tem composto minha prática e buscar sempre ferramentas metodológicas inovadoras e facilitadora no processo de construção conhecimento de atenção à saúde e participação social (FEUERWERKER; SENA, 1999; FAUSTINO; ENGRY, 2002).

Mas, cada passo que tenho dado me aproxima de uma prática motivadora, como demonstro a seguir que

hoje digo que é inegável o quanto os alunos têm mostrado interesse nas aulas
do curso de anatomia, quando estão diante de um caso clínico a qual se propõe
solucionar um problema. A cada caso clínico que recebem, eles conseguem
visualizar a necessidade de terem conhecimento a respeito da disciplina de
anatomia humana, e logo quando percebem que podem colaborar com seus
colegas por meio de suas experiências, para que juntos possam compreender o
problema, isso os motiva por que dá significado ao processo (EXCERTO DO
DIÁRIO DE DOCÊNCIA, 2018).

Em outro panorama, não é mais aprender por aprender, pois hoje temos construído juntos o conhecimento de modo a eliminar desconhecimentos que surgem no processo, além de trazer a realidade da futura vida profissional para as quatro paredes de uma sala. Sabemos que é complexo a busca pelas inovações, entretanto, os resultados gratificam o trabalho docente e como meio de motivar a construção do conhecimento técnicocientíficos dos alunos para com área a Anatomia Humana, de modo a instrumentalizá-los e motivá-los em seu processo formativo (HERMIDA; BARBOSA; HEIDEMANN, 2015).

(III) Potencialidades do uso da PBL na mediação pedagógica para a Educação em Saúde

Início este eixo de análise de um fragmento extraído do diário de docência, no qual há um posicionamento importante para destaque, pois como professora e pesquisadora 
senti grande facilidade em desenvolver todas as fases do grupo tutorial, após muita leitura e pesquisa sobre o uso e aplicação da PBL. Entretanto logo de início a cada sessão de abertura do caso clÍnico, a dificuldade na escolha do coordenador e secretário da sessão tutorial é perceptível, o secretário sente-se na desvantagem, pois para ele além de ter de colaborar com o grupo no estudo do problemas, fazer as anotações para todos me relatam ser cansativo e para também desnecessário; na escolha do coordenador ninguém se manifestava e de fato aceitam por imposição da sequencia organizada, mas, não gostariam de agregar maiores responsabilidade às que já possuíam como integrante do grupo. Além disso, alguns coordenadores parecem de fato não apresentar gosto pela liderança (EXCERTO DO DIÁRIO DE DOCÊNCIA, 2018).

Acredito que a atuação de liderança que a PBL impõe, por meio da responsabilidade dada ao aluno-coordenador sobre o grupo, fará com que o mesmo reconheça ou adquira novas habilidades e possa trabalhar esta nova competência tornando-se pronto para um mercado mais específico após sua formação, inserindo-os em sociedade como pessoa e como profissional na busca de novos conhecimentos e na busca por mudanças e fortalecimento da dinâmica social (KURCGANT, 1991; GIRADE; CRUZ; STEFANELLI, 2006).

Descrevo o quanto percebi que cada aluno tem um tempo de aprendizagem e como o mesmo precisa ser respeitado, além dos êxitos e limitações que a abordagem ABP trouxe a minha prática, uma vez que

\begin{abstract}
na leitura do problema as vezes precisávamos fazê-la de uma a três vezes para que todos os estudantes de fato pudessem compreende-lo, respeitando o tempo do aluno, tendo em vista, que nunca tiveram um paciente antes, nem mesmo casos clínicos fictícios em outras disciplinas; já na identificação e esclarecimento de termos desconhecidos a aula fluía, pois o que um aluno desconhecia o outro já conhecia, de modo que a troca de experiências tornouse constante; na identificação dos problemas propostos pelo enunciado ocorriam algumas tentativas em fugir do foco da anatomia, mas como professora tutora consegui redirecioná-los ao objetivo da aula; novamente a aula fluía na formulação de hipóteses explicativas para os problemas identificados no passo anterior, os alunos se utilizavam nesta fase dos conhecimentos de que dispõem em suas vivências sobre o assunto, sendo visível o quanto os mesmos sentiam-se valorizados em suas contribuições serem consideradas; após tantas contribuições precisávamos fazer um resumo das hipóteses, de modo que o objetivo não era a quantidade de informações mais a qualidade das mesmas; em seguida formulávamos juntos os objetivos de aprendizagem; depois finalizávamos aquela sessão para que todos pudessem realizar o estudo individual nas fontes que os mesmos achassem pertinente; no retorno ao grupo tutorial fazíamos a rediscussão do problema conscientes de que o objetivo não era o de resolvê-lo, mas compreender as contribuições da disciplina no enfrentamento dos casos clínicos que logo após a conclusão do curso se tornarão a realidade destes alunos na carreira profissional (EXCERTO DO DIÁRIO DE DOCÊNCIA, 2018).
\end{abstract}

Para a fase de estudo individual do aluno, refleti que apesar de a pesquisa compor necessariamente um período que deve acontecer por meio da busca pessoal e singular do aluno, não se pode deixar o mesmo desamparado. É preciso que professor se atente: o aluno terá onde buscar este conhecimento, se o mesmo tem acesso à internet, atlas e 
bibliotecas ou outras fontes de dados, para que adquira uma formação mais consolidada com um conjunto de práticas e atenção à saúde, enquanto competência que pessoal, social e profissional que deva ser seguido por toda a vida (PASCHOAL; MANTOVANI; MÉIER, 2007; SILVA; SEIFFERT, 2009).

Nossos planos de aula devem conter uma certa logística; é preciso ser exequível, além de ser nosso dever considerar o acesso do aluno às fontes de pesquisa. Não basta incentivar o aluno a buscar, se o mesmo não tiver tempo para tal dadas suas obrigações familiares ou profissionais ou ainda que não possua acesso às fontes. Reconheço que o aluno poderá buscar soluções em sua própria comunidade e família, entretanto o mesmo é orientado a não traçar totalmente sua base de pesquisa em conhecimentos informais, é necessário pautar-se em conhecimentos científicos, para evitar a simples reprodução de saberes, tendo como meta na Educação em Saúde o aprender constante, enquanto habilidade técnico-científica da sua formação (PASCHOAL; MANTOVANI; MÉIER, $2007 ;)$.

A pesquisa, como forma de conhecer, é uma forma eficaz também de intervir, pois congrega necessariamente a prática com a teoria, constituindo o processo de formação do sujeito crítico, criativo e inventivo, visto que emancipa o sujeito (DEMO, 2005). Alinhada aos estudos de Souza e Ceribelli (2004), trago em um excerto do diário de docência sua visão quanto a utilização de materiais didáticos como recursos diversificados,

\begin{abstract}
devido alguns alunos não possuírem acesso às fontes de informação científica fora da escola, tenho destinado um tempo para que os mesmos possam ter acesso aos modelos plásticos anatômicos do laboratório, ao laboratório de informática e aos atlas anatômicos da biblioteca fora do horário de aula. Pois, acredito que facilitar o acesso dos alunos aos materiais didáticos já existentes na escola, não desvia o caminho do processo de aprendizado autônomo, mas intensifica a construção significativa do conhecimento. $\mathrm{O}$ aluno poderá se tornar melhor capacitado para a investigação quando porta de meios significativos para busca de soluções ao seu caso clínico (EXCERTO DO DIÁRIO DE DOCÊNCIA, 2018).
\end{abstract}

Para finalizar, destaco que não tenho intenção de dizer que a abordagem PBL esgota as possibilidades de uso de outras abordagens metodológicas eficazes para o ensino-aprendizagem da Educação em Saúde, mas que a mesma é uma opção bastante utilizada nos cursos de Ciências da Saúde e tem se mostrado com resultados satisfatórios (BERBEL, 1988; IERVOLINO; PELICIONI, 2001; SOUSA; CERIBELLI, 2004; SCHAURICH; CABRAL; ALMEIDA, 2007; SOUSA, 2010). Ao usar esta abordagem, destaco que a prática docente reflexiva ocorre antes, durante e depois de todo planejamento de ensino e, em um curso profissionalizante, além de o uso de problemas 
permeia a construção de conhecimentos, habilidades e o desenvolvimento da autonomia discente.

Seguindo as ideias de Iervolino e Pelicioni (2001) e Borges et al. (2014), notadamente observamos que o uso de grupos tutoriais, outras atividades e outros profissionais além do tutor também são elementos essenciais na PBL, como o treinamento de habilidades, aulas práticas, estágios, consultorias com especialistas, entre outras, a fim de complementar a formação dos estudantes.

\section{Tecendo considerações}

Percebemos que de fato ainda existem para alguns docentes muitas limitações, mas que apesar disso, é possível ao professor tornar sua prática significativa para a formação dos alunos. A base pedagógica deficiente do professor da saúde tem dificultado sua propriedade aos elementos didáticos e a relação do ensino com o trabalho conferem à educação profissional um caráter ainda mais desafiador, por exigir do professor práticas significativas e motivadoras.

Considerando que a disciplina Anatomia Humana é de extrema necessidade a formação do profissional da saúde, é que os alunos possuem grande dificuldade na apreensão deste conhecimento por meios tradicionais de ensino, acredito que a simples transmissão de conteúdo deve ser evitada, buscando formas de construir conjuntamente, professor e aluno, o conhecimento necessário.

Neste sentido, a PBL, proporciona meios à educação, que os tornam significativos, nos quais o estudante possa compreender problemas atuais da sociedade ainda em sala de aula, buscando soluções a estes através da investigação, que baseada na prática da educação em saúde, torna o futuro profissional técnico em enfermagem capaz de agir nas necessidades de sua comunidade.

A abordagem PBL é de fato um método ativo de ensino que confere ao processo educativo, a capacidade de integrar a realidade do aluno à sua educação. Os passos da sessão tutorial se bem direcionados, levam os alunos a autonomia, os tornam investigadores em potencial, além de despertar nos mesmos a confiança de poderem seguir na área que se propunham, seja a assistência clínica, a educação ou a gestão.

Voltando nossos olhares acerca do objetivo proposto inicialmente, destacamos que o percurso metodológico desenhado pela pesquisa de intervenção pedagógica conseguiu emergir elementos autobiográficos importantes da prática pedagógica do 
professor enfermeiro que atua na educação profissional. Para além do exposto, frisamos que os elementos da prática reflexiva fazem com que o professor reavive a sua dimica pedagógica, com vistas à construção de conhecimentos técnico-científicos em enfermagem, de modo a atender os anseios individuais e coletivos da formação de um profissional, conforme os pressupostos da Educação em Saúde.

Portanto, é preciso que aprendamos a refletir sobre nossa própria prática e possamos, desta maneira, contribuir para melhorias na Educação em Saúde, pois, para que tenhamos equipes de enfermagem humanizadas na assistência clínica, é preciso que a construção do conhecimento destes profissionais seja feita de forma integral e humanizada por professores conhecedores dos melhores métodos didáticos.

\section{Referências}

BARBOSA, Thiago Luis de Andrade et al. Expectativas e percepções dos estudantes do curso técnico em enfermagem com relação ao mercado de trabalho. Texto \& Contexto -

Enfermagem, Florianópolis, v. 20, n. spe, p. 45-51. 2011. DOI:

http://dx.doi.org/10.1590/S0104-07072011000500005

BACKES, Dirce Stein et al. Repensando o ser enfermeiro docente na perspectiva do pensamento complexo. Revista Brasileira de Enfermagem, Brasília - DF, v. 63, n. 3, p. 421426, maio./jun. 2010. DOI: http://dx.doi.org/10.1590/S0034-71672010000300012

BECKER, Fernando. Educação e construção do conhecimento. 2. ed. Porto Alegre: Penso, 2012.

BERBEL, Neusi Aparecida Narvas. A problematização e a aprendizagem baseada em problemas. Interface, Comunicação, Saúde e Educação, Botucatu. v. 2, n. 2, p. 139-154, fevereiro. 1998. DOI: http://dx.doi.org/10.1590/S1414-32831998000100008

BORGES, Marcos de Carvalho; CHACHÁ, Silvana; QUINTANA, Silvana; FREITAS, Luiz Carlos; RODRIGUES, Maria Lourdes. Aprendizado baseado em problemas. Medicina, Ribeirão Preto, v. 47, n. 3, p. 301-307. 2014. Disponível em: http://revista.fmrp.usp.br/2014/vol47n3/8_Aprendizado-baseado-em-problemas.pdf. Acesso em: 25 set. 2018.

BORGES, T. S; ALENCAR, G. Metodologias ativas na promoção da formação crítica do estudante: o uso das metodologias ativas como recurso didático na formação crítica do estudante do ensino superior. Cairu em Revista, Salvador, v. 3, n. 4, p. 119-143, jul./ago. 2014.

Disponível em: https://www.cairu.br/revista/arquivos/artigos/2014 2/08\%20METODOLOGIAS\%20ATIVAS\%20NA\%20PROMOCAO\%20DA\%20FORMACA O\%20CRITICA\%20DO\%20ESTUDANTE.pdf. Acesso em: 25 set. 2018.

BRASIL. Senado Federal. Lei no 9.394, 20 de dezembro de 1996: Lei de Diretrizes e bases da Educação, Brasília, dez. 1996. Disponível em: http://www.planalto.gov.br/ccivil_03/Leis/19394.htm. Acesso em: 31 maio. 2018. 
BRASIL. Ministério da Saúde (MS). Secretaria de Gestão do Trabalho e da Educação na Saúde. Departamento de Gestão e da Regulação do Trabalho em Saúde. Câmara de Regulação do Trabalho em Saúde. Brasília: MS, 2006.

BRAZ, P. R. P. Método didático aplicado ao ensino da anatomia humana. Anuário da Produção Acadêmica Docente, São Paulo, v. III, n. 4, p. 303-310, abr. 2009. Disponível em: https://repositorio.pgsskroton.com.br/bitstream/123456789/1342/1/Artigo\%2020.pdf. Acesso em: 25 set. 2018.

COSTA, Gilliene Batista Ferreira; COSTA, Gilliane Batista Ferreira; LINS, Carla Cabral dos Santos Accioly. O cadáver no ensino da anatomia humana: uma visão metodológica e bioética. Revista Brasileira de Educação Médica, Pernambuco, v. 36, n. 3, p. 369-373, 2012. DOI: http://dx.doi.org/10.1590/S0100-55022012000500011

CARDOSO, J. L. da S.; MONTEIRO, A. L. Professor bacharel na educação profissional e tecnológica: a busca por identidades e o trabalho docente. Revista Margens Interdisciplinar, Belém. v. 11, n. 16, p. 16, jun. 2018. Disponível em:

https://periodicos.ufpa.br/index.php/revistamargens/article/viewFile/5387/4507. Acesso em: 25 set. 2018.

COSTA, A. C. G. da. O Professor como Educador. Salvador: FLEM, 2001.

DAMASCENO, S. A. N.; CÓRIA-SABINI, M. A. Ensinar e aprender: saberes e práticas de professores de anatomia humana. Revista Psicopedagogia, Nova Iguaçu, v. 20, n. 63, p. 11, 2003. Disponível em: http://www.revistapsicopedagogia.com.br /detalhes/286/ensinar-eaprender--saberes-e-praticas-de-professores-de-anatomia-humana. Acesso em: 25 set. 2018.

DEMO, P. Educar pela pesquisa. Campinas: Autores Associados, 2005.

DIAS, E. S. M. et al. Roda de conversa como estratégia de educação em saúde para a enfermagem. Revista Online de pesquisa, Rio de Janeiro, v.10, n.2, p. 379-384, jun. 2018. DOI: http://dx.doi.org/10.9789/2175-5361.2018.v10i2.379-384

FERNANDES, J. D. et al. Diretrizes curriculares e estratégias para implantação de uma nova proposta pedagógica. Revista Escola de Enfermagem USP, São Paulo. v. 39, n. 4, p.443-449. 2005. DOI: http://dx.doi.org/10.1590/S0080-62342005000400011

FAUSTINO, R. L. H.; EGRY, E. Y. A formação da enfermeira na perspectiva da educação: reflexões e desafios para o futuro. Rev Esc Enferm USP, São Paulo. v. 36, n. 4, p.332-337. 2002. DOI: http://dx.doi.org/10.1590/S0080-62342002000400006

FERRAROTI, F. Sobre a autonomia do método autobiográfico. In: FINGER, M.; NÓVOA, A. (org.). O método (auto) biográfico e a formação. Caderno de formação 1. Lisboa: Ministério da Saúde, 1988. p.19-34.

FEUERWERKER, L.C.M., SENA, R. A construção de novos modelos acadêmicos, de atenção à Saúde e de participação social. In: ALMEIDA, M.J., FEUERWERKER, L.C.M., LLANOS, M. A Educação dos profissionais de saúde na América Latina: teoria e prática de um movimento de mudança. São Paulo: HUCITEC, 1999. p.47-83

FORNAZIERO, C. C. et al. O ensino da anatomia: integração do corpo humano e meio ambiente. Revista Brasileira de Educação Médica, Brasília. v. 34, n. 2, p. 290-297, 2010. DOI: http://dx.doi.org/10.1590/S0100-55022010000200014 
GIRADE, M. da G.; CRUZ, E. M. N. T. da.; STEFANELLI, M. C. Educação continuada em enfermagem psiquiátrica: reflexão sobre conceitos. Revista da Escola de Enfermagem da USP, São Paulo. v. 40, n. 1, p. 105-110, mar. 2006. DOI: http://dx.doi.org/10.1590/S008062342006000100015

GOMES, L. C. G. As escolas de aprendizes artífices e o ensino profissional na velha república. Vertices, São Paulo v. 5, n. 3, p. 53-80, set-dez 2010.

HERMIDA, P. M. V.; BARBOSA, S. S.; HEIDEMANN, I. T. S. B. Metodologia ativa de ensino na formação do enfermeiro: inovação na atenção básica. Revista de Enfermagem da UFSM, Santa Maria. v. 5, n. 4, p. 683-691, out./dez. 2015.

DOI: http://dx.doi.org/10.5902/2179769216920

IERVOLINO, S. A.; PELICIONI, M. C. F. A utilização do grupo focal como metodologia qualitativa na promoção da saúde. Revista da Escola de Enfermagem da USP, São Paulo. v. 35, n. 2, p. 115-121, 2001. DOI: http://dx.doi.org/10.1590/S0080-62342001000200004

KLETEMBERG, D. F.; SIQUEIRA, M. T. A. Dalledone. A criação do ensino de enfermagem no Brasil. Cogitare Enfermagem, Curitiba. v. 8, n. 2, p. 30-78. 2003. DOI:

http://dx.doi.org/10.5380/ce.v8i2.1695

KURCGANT, P. Administração em enfermagem. São Paulo: Editora Pedagógica e Universitária Ltda, 1991.

LIBÂNEO, J. C. Didática. 34 ed. São Paulo: Cortez, 2017.

LIMA, E. C.; APPOLINÁRIO, R. S. A educação profissionalizante em enfermagem no Brasil: desafios e perspectivas. Revista de Enfermagem da UERJ, Rio de janeiro. v. 19, n. 2, p. 311316, abr./jun. 2011. Disponível em: http://www.facenf.uerj.br/v19n2/v19n2a23.pdf. Acesso em: 25 set. 2018.

LUCKESI, C. C. Avaliação da Aprendizagem escola: estudos e proposições. São Paulo: Cortez Editora, 2014.

MARTIN, J. Cultures in organizations: Three persctives. New York: Oxford University Press, 1992.

MIRANDA-JUNIOR, U. J. P. de. Problem Based Learning como metodologia inovadora no ensino de graduação em saúde. Revista Portuguesa de Medicina Geral e Familiar. Lisboa. v. 32, n. 1, p. 12-13, fev. 2016. Disponível em:

http://www.scielo.mec.pt/pdf/rpmgf/v32n1/v32n1a03.pdf. Acesso em: 25 set. 2018.

MORAES, R.; GALIAZZI, M. do C. Análise Textual Discursiva. 2. ed. Ijuí: Editora Unijuí, 2016.

MOURA, D. H. A formação de docentes para a educação profissional e tecnológica. Revista Brasileira da Educação Profissional e Tecnológica, Natal. v. 1, n. 1, p. 23-38, jul. 2008. DOI: https://doi.org/10.15628/rbept.2008.2863

OLIVEIRA, V. S. de; SILVA, R. de F. Ser bacharel e professor: dilemas na formação de docentes para a educação profisssional e ensino superior. Holos, Natal, v. 2, n. 28, p. 193205.2012. DOI: https://doi.org/10.15628/holos.2012.913 
OLIVEIRA, I.; SERRAZINA, L. A reflexão e o professor como investigador. Refletir e investigar sobre a prática profissional, Lisboa. v. 29, n. 72, p. 29-42, abr./jun. 2002. Disponível em: http://apm.pt/files/127552_gti2002_art_pp29-42_49c770d5d8245.pdf. Acesso em: 25 set. 2018.

PASCHOAL, A. S.; MANTOVANI, M. de F.; MÉIER, M. J. Percepção da educação permanente, continuada e em serviço para enfermeiros de um hospital de ensino. Revista da Escola de Enfermagem da USP, Saó Paulo. v. 41, n. 3, p. 478-484, 2007. DOI: http://dx.doi.org/10.1590/S0080-62342007000300019

PEREIRA, S. E. Contribuições para um planejamento educacional em ciências da saúde com estratégias inovadoras de ensino-aprendizagem. Comunicação em Ciências da Saúde, Brasília, v.18, n.1, p. 33-44, 2007. Disponível em:

http://www.escs.edu.br/pesquisa/revista/2007Vol18_1art04contribuicoes.pdf. Acesso em: 25 set. 2018.

REIS, C. et al. Avaliação da percepção de discentes do curso médico acerca do estudo anatômico. Revista Brasileira de Educação Médica, Brasília. v. 37, n. 3, p. 350-358. 2013. DOI: http://dx.doi.org/10.1590/S0100-55022013000300007

RODRIGUES-MOURA, Se. Avaliação em Aulas de Ciências e Matemáticas: narrativa (auto)biográfica como instrumento de formação do professor-pesquisador. Boletim On-Line de Educação Matemática, Joinville, v. 4, n. 6, p. 28-47, 2016. Disponível em http://www.revistas.udesc.br/index.php/boem/article/view/7463. Acesso em: 25 set. 2018.

SALBEGO, C. et al. Percepções acadêmicas sobre o ensino e a aprendizagem em anatomia humana. Revista Brasileira de Educação Médica, Brasília. v.39, n.1, p.23-31, 2015. DOI: http://dx.doi.org/10.1590/1981-52712015v39n1e00732014

SEVERINO, A. J. Metodologia do trabalho científico. 23. ed. São Paulo: Cortez, 2007.

SCHAURICH, D.; CABRAL, F. B.; ALMEIDA, M. de A. Metodologia da problematização no ensino em Enfermagem: uma reflexão do vivido no Profae/RS. Revista de Enfermagem, Rio de janeiro. v. 1, n. 2, p. 318-324, jun. 2007. DOI: http://dx.doi.org/10.1590/S1414$\underline{81452007000200021}$

SILVA, G. M. da; SEIFFERT, O. M. da L. B. Educação continuada em enfermagem: uma proposta metodológica. Revista Brasileira de Enfermagem, Brasília. v. 62, n. 3, p. 362-366, maio-jun. 2009. DOI: http://dx.doi.org/10.1590/S0034-71672009000300005

SOUSA, S. de O. Aprendizagem baseada em problemas como estratégia para promover a inserção transformadora na sociedade. Acta Scientiarum Education, Maringá. v. 32, n. 2, p. 237-245. 2010. DOI: https://doi.org/10.4025/actascieduc.v32i2.11170

SOUZA, M. C. B. de; CERIBELLI, M. I. P. de F. Enfermagem no centro de material esterilizado a prática da educação continuada. Revista Latino Americana de Enfermagem, Ribeirão Preto. v. 15, n. 5, p. 767-774, set./out. 2004. DOI: http://dx.doi.org/10.1590/S0104$\underline{11692004000500010}$

VIGNOCHI, C. M. et al. Considerações sobre aprendizagem baseada em problemas na educação em saúde. Revista HCPA, Porto Alegre, v. 29, n. 1, p. 45-50. 2009. Disponível em: https://www.lume.ufrgs.br/bitstream/handle/10183/157866/000829624.pdf?sequence=1\&isAllo wed=y. Acesso em: 25 set. 2018. 
WALL, M. L.; PRADO, M. L. do; CARRARO, T. E. A experiência de realizar um Estágio Docência aplicando metodologias ativas. Acta Paulista de Enfermagem, São Paulo, v. 21, n. 3, p. 515- 519. 2008. DOI: http://dx.doi.org/10.1590/S0103-21002008000300022

Recebido em: 14 de janeiro de 2019.

Aceito em: 06 de outubro de 2019. 